\title{
Seismic Expression of Polygonal Faults and Its Impact on Fluid Flow Migration for Gas Hydrates Formation in Deep Water of the South China Sea
}

\author{
Duanxin Chen, ${ }^{1,2}$ Shiguo Wu, ${ }^{1}$ Xiujuan Wang, ${ }^{1}$ and Fuliang $\mathrm{Lv}^{3}$ \\ ${ }^{1}$ Key Laboratory of Marine Geology and Environment, Institute of Oceanology, Chinese Academy of Sciences, \\ Qingdao 266071, China \\ ${ }^{2}$ Graduate University of Chinese Academy of Sciences, Beijing 100049, China \\ ${ }^{3}$ Hangzhou Institute of Geology, PetroChina, Hangzhou 310023, China \\ Correspondence should be addressed to Shiguo Wu, swu@qdio.ac.cn
}

Received 31 May 2011; Revised 2 September 2011; Accepted 12 September 2011

Academic Editor: Ingo Pecher

Copyright (C) 2011 Duanxin Chen et al. This is an open access article distributed under the Creative Commons Attribution License, which permits unrestricted use, distribution, and reproduction in any medium, provided the original work is properly cited.

Polygonal faults were identified from three-dimensional (3D) seismic data in the middle-late Miocene marine sequences of the South China Sea. Polygonal faults in the study area are normal faults with fault lengths ranging from 100 to $1500 \mathrm{~m}$, fault spaces ranging from 40 to $800 \mathrm{~m}$, and throws ranging from 10 to $40 \mathrm{~m}$. Gas hydrate was inferred from the seismic polarity, the reflection strength, and the temperature-pressure equilibrium computation results. Gas hydrates located in the sediments above the polygonal faults layer. Polygonal faults can act as pathways for the migration of fluid flow, which can supply hydrocarbons for the formation of gas hydrates.

\section{Introduction}

Polygonal faults are a network of layer-bound, mesoscale (throws from 10 to $100 \mathrm{~m}$ ) extensional faults arranged in a polygonal structure developing in deep-water sequence [1]. The term "polygonal fault" was named by Cartwright [2] when he analyzed the shale sedimentary throughout the 3D seismic data obtained from North Sea basin. Up to now, more than 50 basins have found the existence of polygonal faults. Some geologists presented different formation mechanisms, including density inversion $[3,4]$, gravity sliding or collapse [5], episodic hydrofracturing [6], "volumetric contraction" [7], and low coefficients of friction [8].

In the South China Sea (SCS), polygonal faults were for the first time identified in the Qiongdongnan basin (QDNB) in 2009 [9]. Sun et al. [10] mentioned the migration of hydrocarbon through polygonal faults in QDNB. However, there is no document about reservoirs of gas hydrates associated with polygonal faults in SCS.

In this paper, we will show the seismic geometry and distribution of polygonal faults and investigate the geophysical characters of gas hydrates in deep water of QDNB and Zhongjiannan basin (ZJNB) (Figure 1). We use highresolution $2 \mathrm{D}$ and $3 \mathrm{D}$ seismic data integrated with local sedimentary history to study the function of polygonal faults in acting as conduits of gas hydrate provinces.

\section{Geological Backgrounds}

Sedimentary basins in northern South China Sea margin underwent an early syn-rifting stage in Paleogene and a postrifting thermal subsidence stage in Neogene and Quaternary [11]. The separation for syn-rifting and postrifting stage is a breakup unconformity T60 (stratigraphic frames listed in Figure 2) between Oligocene and Miocene. Sedimentary facies in syn-rifting stage chiefly evolved from alluvial, delta, and lacustrine facies to shallow marine facies, whereas shallow, bathyal, and abyssal facies occupied the postrifting stage [11]. Sediments in lower Huangliu formation and upper Meishan formation of Miocene sequence consist of fine-grained claystone and limestone-hosting polygonal faults based on wireline log interpretations from wells drilled in QDNB. 


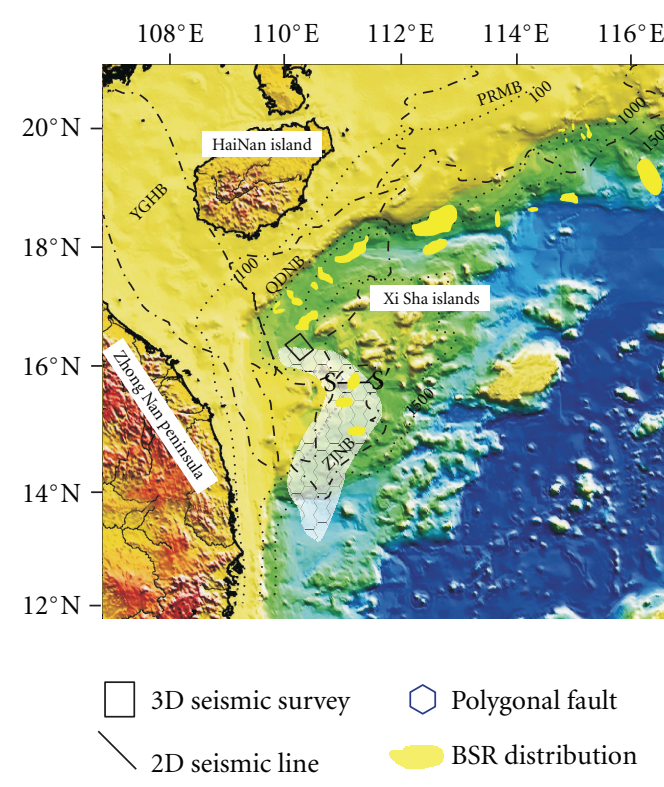

(a)
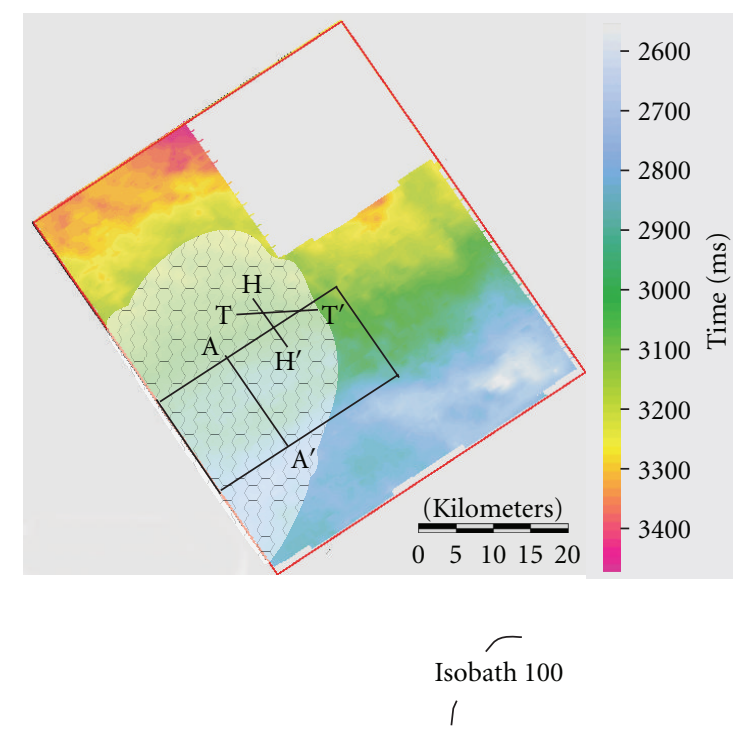

(b)

Figure 1: (a) The schematic map of South China Sea. The map shows the distribution of polygonal faults and prospective gas hydrate zones in QDNB and ZJNB. (b) The 3D seismic survey in deep water of QDNB. The basemap is the time depth of the sequence boundary of the base of upper Miocene. Lines plotted in the map will be discussed below.

\section{Data and Methodology}

This study is based on an integrated analysis of seismic data including a 3D survey and 2D lines acquired by BGP Inc., (China National Petroleum Corporation (CNPC)), processed by Liaohe Petroleum (CNPC, PetroChina). The $3 \mathrm{D}$ seismic data covers an area of $1480 \mathrm{~km}^{2}$ with a bin size of $12.5 \mathrm{~m} \times 25 \mathrm{~m}$ and water depth ranging from $1120 \mathrm{~m}$ to $1275 \mathrm{~m}$ in west of Xisha Islands, while 2D seismic data covers the deepwater of the southern depression of QDNB and the overall ZJNB with the common depth point (CDP) interval of $25 \mathrm{~m}$ (Figure 1(a)). We used the coherency slice and sequence flattening technique to study the $3 \mathrm{D}$ and partial $2 \mathrm{D}$ seismic data. With estimated geothermal gradient values and proper formation velocities, the study utilizes temperaturepressure equilibrium to compute the base of GHSZ.

\section{Results}

4.1. Seismic Imaging to Identify Polygonal Faults. Polygonal faults were identified in deep water of the southern depression of QDNB and northeastern of ZJNB over an area of about $6000 \mathrm{~km}^{2}$ (Figure 1(a)). 3D seismic data from QDNB indicated that the polygonal faults pervasively occur in the lower Huangliu formation and upper Meishan formation and are limited by layer-bound strata of the base of Pliocene (T30) and Meishan formation (T50), as seen in Figure 3. Polygonal faults in northern SCS are extensional faults with fault lengths ranging from 100 to $1500 \mathrm{~m}$, fault spaces ranging from 40 to $800 \mathrm{~m}$, and throws ranging from 10 to $40 \mathrm{~m}$ (Figures 3 and 4 ). The view of the coherence slice from the $3 \mathrm{D}$ seismic data shows the irregular polygonal map geometry (Figure 4). The deformed interval is generally subdivided into two tiers. The upper tier lies in the layer of 2.5-2.7 s two-way travel time (TWT)and the lower one is in the layer of $2.7-3.0 \mathrm{~s}$ (TWT), manifesting the stratigraphically delimited subunits within the deformed interval. However, faults with longer vertical slip may connect the two tiers, piercing the base of Pliocene and Meishan formation. Smaller faults could be found dim among distinct polygonal faults (Figure 4). It might indicate the existence of smaller scale of polygonal faults.

4.2. BSRs Occurrence in Deep Water of SCS. Distributions and characteristics of BSRs in deep water of QDNB have been delineated (Figure 1(a)) [12-16]. Most of the BSRs with middle- to- high amplitude develop in Neogene and Quaternary strata which are paralleling to the seafloor.

We calculated the base of GHSZ and plotted it in seismic profile $\mathrm{SS}^{\prime}$ in Figure 5 using the geothermal gradient and water depth obtained from this basin. The geothermal gradient was $0.045^{\circ} \mathrm{Cm}^{-1}$ suggested by $\mathrm{Ma}$ et al. [17]. The water depth was acquired in accordance with multibeam data.

Temperature-pressure equilibrium equation was given by Miles [18]

$$
P=2.8074023+a \cdot T+b \cdot T^{2}+c \cdot T^{3}+d \cdot T^{4},
$$

where $P(\mathrm{MPa})$ is the formation pressure; $T\left({ }^{\circ} \mathrm{C}\right)$ is formation temperature; $a=1.559574 \times 10^{-1} ; b=4.8275 \times 10^{-2}$; $c=-2.78083 \times 10^{-3} ; d=1.5922 \times 10^{-4}$. And values of parameters $(a-d)$ were used by Wang et al. [19].

In (1), the input water depth is $1100 \mathrm{~m}$ and the geothermal gradient is $0.045^{\circ} \mathrm{C} \mathrm{m}^{-1}$. The thickness of base of GHSZ 


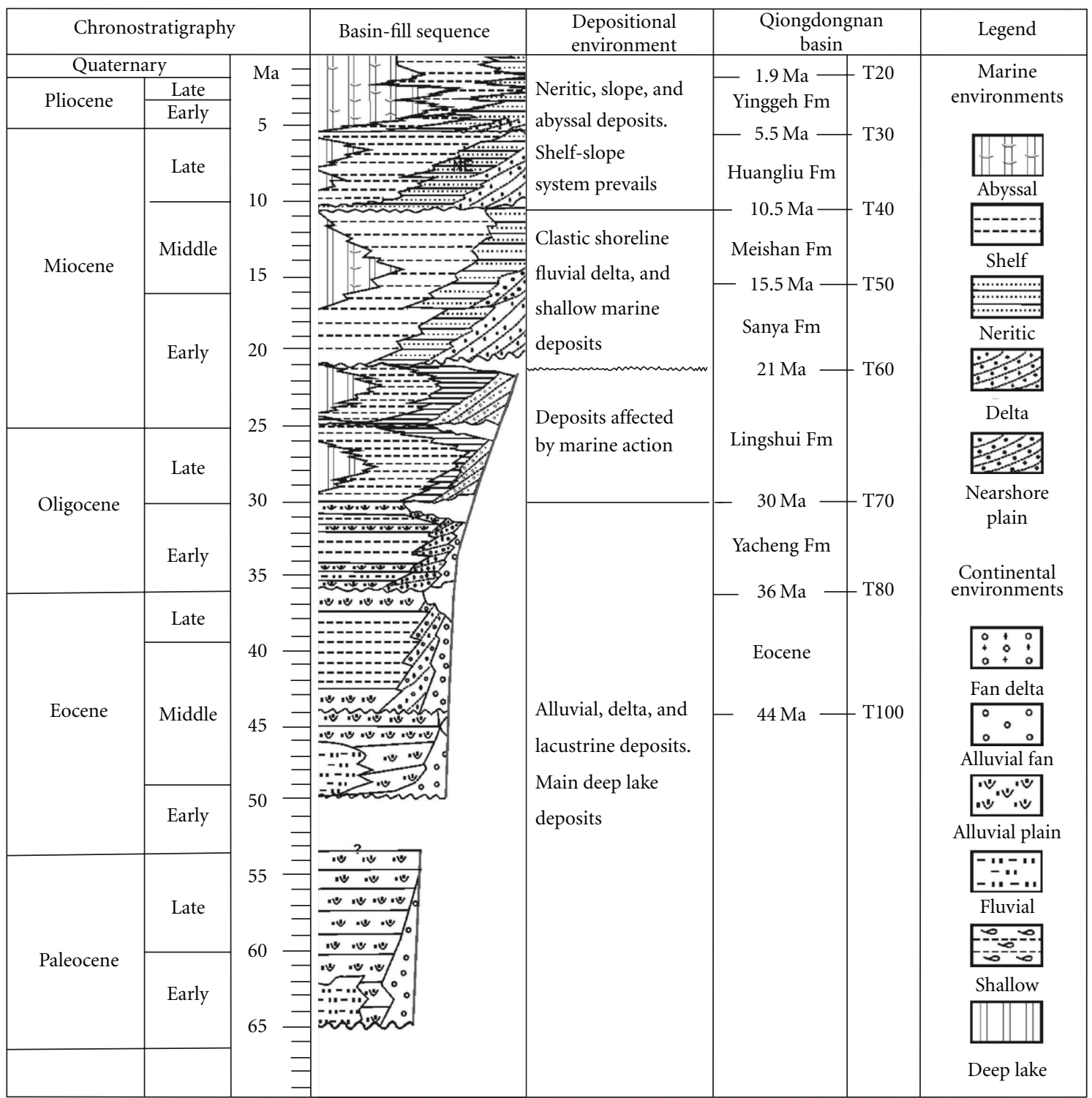

FIGURE 2: Chronostratigraphy chart illustrating the basin-fill sequence and depositional environment of QDNB and ZJNB, modified from Xie et al. [11].

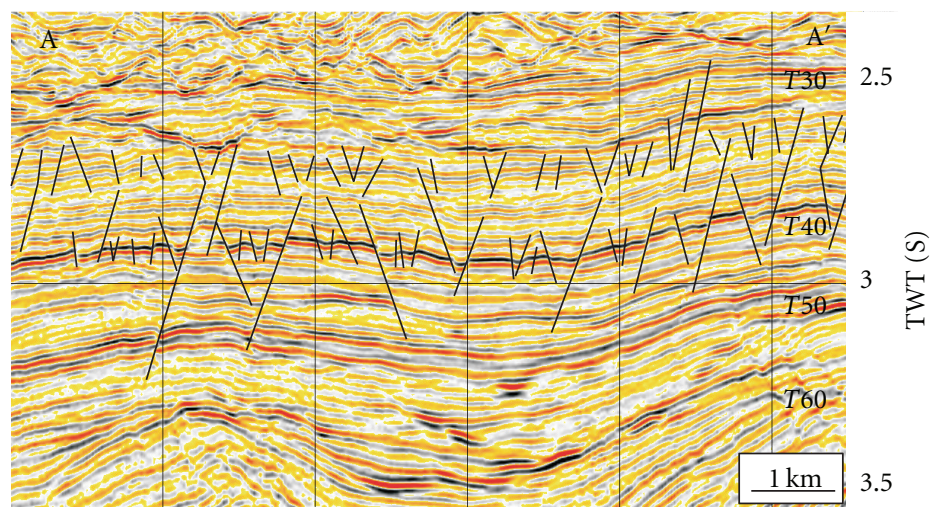

FIGURE 3: Seismic profile of line AA' showing vertical characteristics of polygonal faults, for example normal faults with throws ranging from 10 to $40 \mathrm{~m}$, fault spaces from 40 to $800 \mathrm{~m}$, and two tiers visible. 


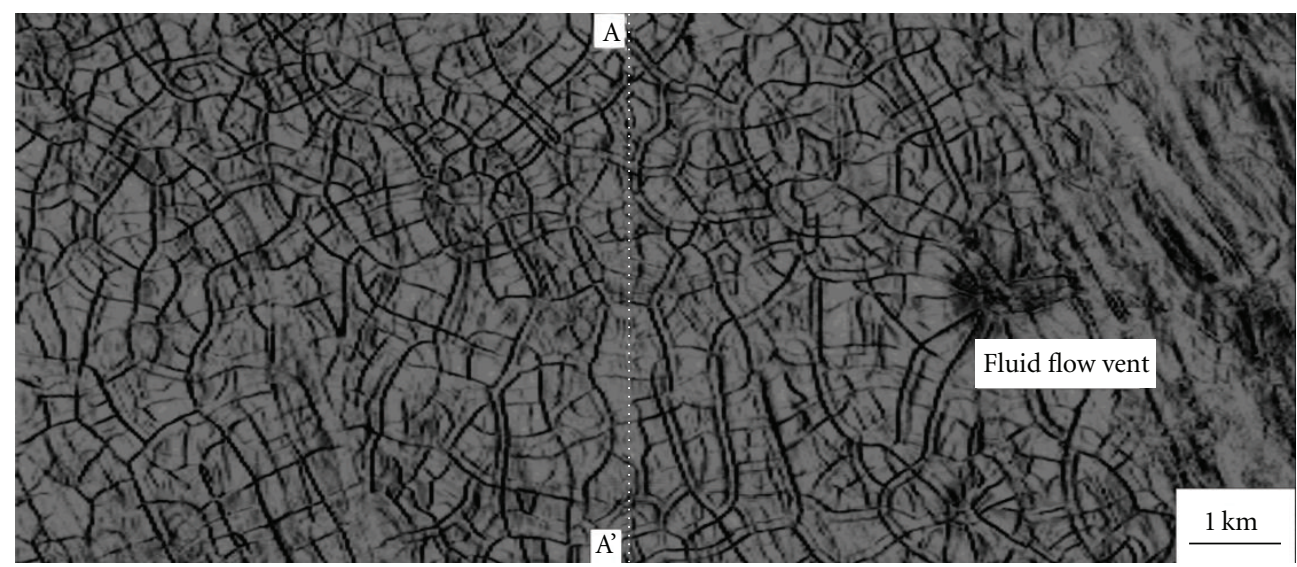

FIgure 4: Coherence slice through the T40 horizon. The polygonal geometry is visible in the map. The rectangle boundary and vertical seismic profile of line $\mathrm{AA}^{\prime}$ are displayed in Figure 1(b). The vent may have formed as a result of expelled fluid flow.

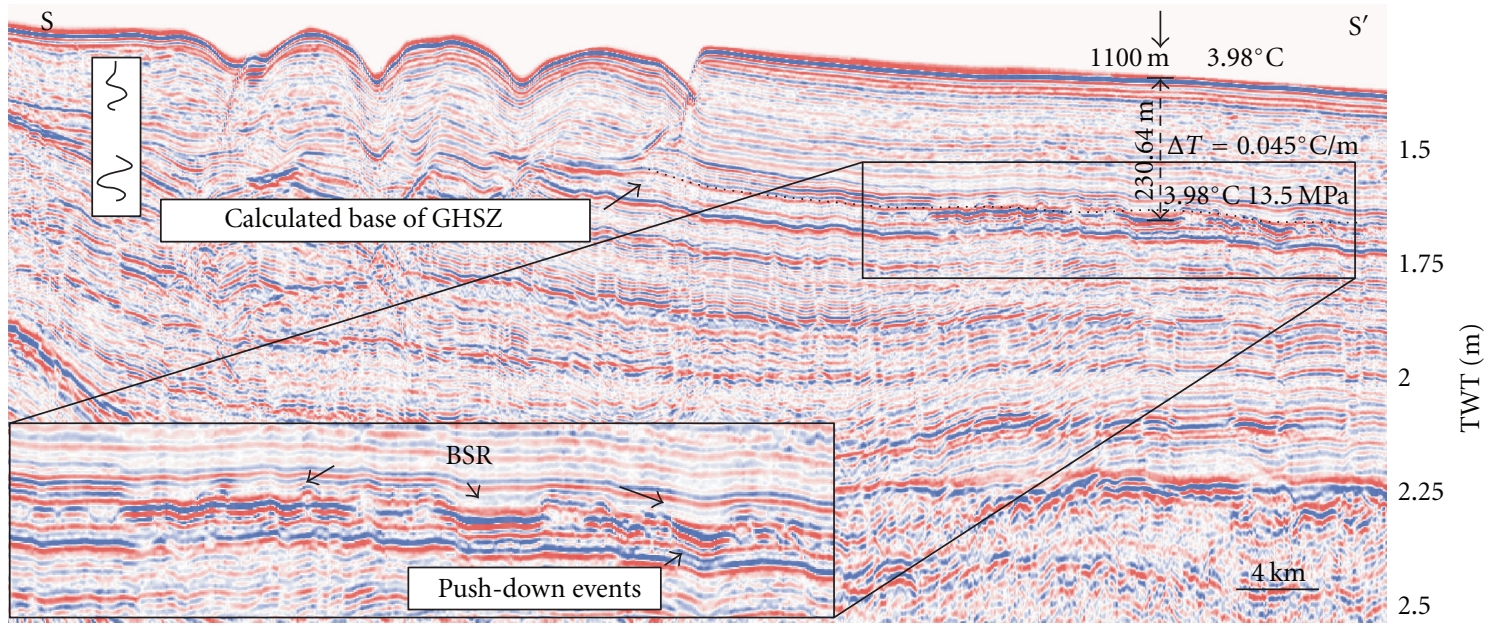

FIgURE 5: The calculated depth of GHSZ, and heat flow values in seismic profile SS'.

is $230.64 \mathrm{~m}$ and the pressure of the BSR is about $13.53 \mathrm{MPa}$. The conductivity is $1.18792 \mathrm{Wm}^{-1}{ }^{\circ} \mathrm{C}^{-1}$, and heat flow value at the BSR is $53.456 \mathrm{mWm}^{-2}$. The result is plotted in Figure 5. Heat flow value is in accordance with $\mathrm{He}$ et al. [20], who proposed that the average heat flow was about $59 \mathrm{mWm}^{-2}$ which was caused by the high rate of sedimentation. The estimated thickness of GHSZ also coincides with the values given by Jin et al. [21] and Shi et al. [22] in this area.

\section{Discussions}

5.1. Focused Fluid Flow Associated with Polygonal Fault. Many people have reported the existence of pockmarks, gas chimneys, mud diapirs, slides, and channels and discussed their relationship to the fluid flow in northern South China Sea $[14,16,19,23,24]$. However, the polygonal faults may provide an additional pathway for the fluid flow, and the relationship has also been documented in the Lower Congo Basin [25], Norway continental margin [26, 27], and Scotian slope of the eastern Canada continental margin [28].

In QDNB and ZJNB, a large volume of source rocks and syn-rift faults were well developed in the Paleogene sequences, whereas few faults occurred in the postrifting stage in deep water, which limited deep hydrocarbon in synrifting strata to migrate upward into the post-rifting strata. Therefore, polygonal faults developing in the lower Huangliu formation and the upper Meishan formation provide enhanced permeability for the fine-grained claystone and act as a pathway linking source rock in the syn-rifting strata to the reservoir in the post-rifting strata which may release more hydrocarbons migrating upwards the base of GHSZ.

Fluid flow involved in mud diaper, upwelling along a polygonal fault, indicates that polygonal faults may serve as fluid flow conduits, as shown in Figure 6. In the section, fluid flow commenced its migration through the lower tier of polygonal faults. Acoustic blanking zones and strong reflectors above sacking structures indicate the presence of gas. A small amount of fluid could also flow upwards via the upper tier. Polygonal faults display a radiant shape, as shown in Figure 4.

The model of low coefficient of friction raised by Goulty [8] may support the function of conduits of polygonal faults as well as conventional faults. It was demonstrated that low coefficients of residual friction in fine-grained sediments 


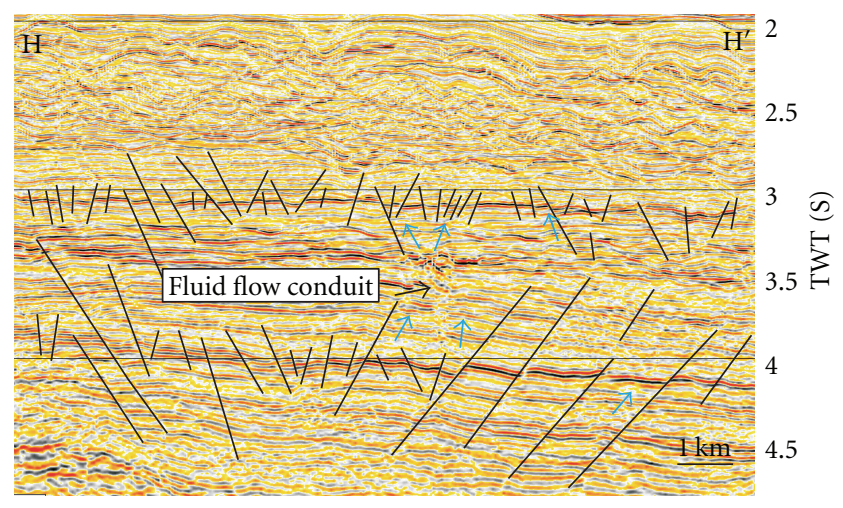

FIGURE 6: Interpretation of seismic profile $\mathrm{HH}^{\prime}$, which describes the migration of fluid flow through polygonal faults. The dim seismic reflectors and fluid flow pipes are visible. See position in Figure 1(b).

might be key to the formation of the polygonal system, and there was no evidence that nucleation of those faults that evolve into polygonal systems differs fundamentally from the processes involved in the nucleation of conventional faults in soft sediments [8]. Previous studies show that polygonal faults often initiate at shallow burial depth $[2,7$, 29]. With increasing buried depth, compacted dewatering continuously occurs in layers underlying polygonal faults, and expelled fluids migrate up through polygonal faults and rock porosities to arrive at the seabed. However, with relation to different formation models of polygonal faults, the transporting mechanisms of fluid flows through polygonal faults are controversial $[6,8]$. The preferred way of fluid flows may be episode eruptions provided by Cartwright [6]. Roberts and Nunn (1995) also conducted numerical simulations showing that a vertical fracture opened for 20-50 years in the seal and provided a permeable pathway from the geopressured sediments into the overlying section when the fluid pressure exceeds $85 \%$ of the lithostatic pressure. Then Fluid pressure in the seal decreased, and the fracture closed until fluid pressure increased to the fracture criteria, which took $10.000-500.000$ years [30].

5.2. Gas Hydrate Occurrence with Polygonal Faults. The fact that deep fluid flows upwell through polygonal faults to produce gas hydrates is confirmed in several basins. The relationship between the polygonal fault and gas hydrate has been discussed on the continental margin of Norway, the Lower Congo basin, and the Scotian margin of the east coast of Canada $[23,24,26]$. On the mid-Norwegian margin, the polygonal fault system is located in the fine-grained hemipelagic sediments of the Kai formation, showing that fluid flow related to polygonal fault in this area is an ongoing process since the early Miocene in the mid-Norwegian $[26,27]$.

Besides tectonic faults, diapirs, and gas chimney act as conduits for the reservoir of gas hydrates in the South China Sea; the polygonal fault system is considered to be a new pathway linking to the GHSZ. The BSRs locate at the base of GHSZ which may indicate the presence of gas hydrates. The distribution of BSRs is shown in Figure 1(a). The BSRs

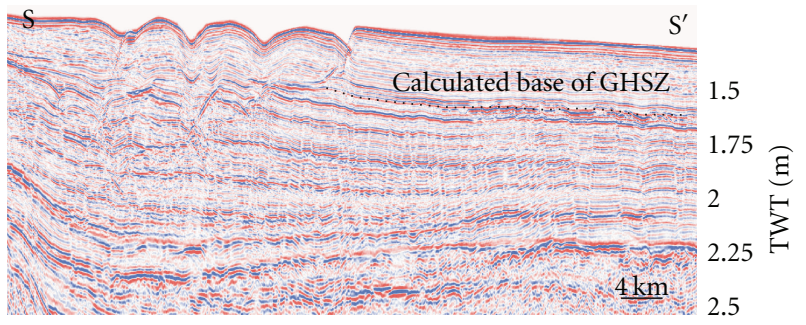

(a)

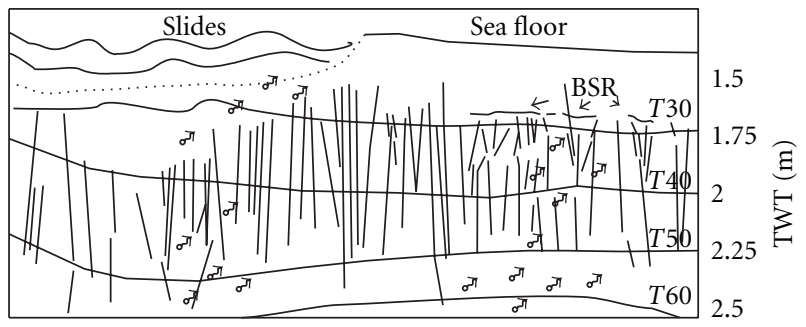

(b)

FIgure 7: (a) The seismic profile SS'. (b) The interpretation of line $\mathrm{SS}^{\prime}$. The figure shows fluid flow migrated into the GHSZ through the polygonal faults. BSRs are distinctly visible overlying the polygonal faults. See the position in Figure 1(a).

are discontinuous and occur overlying the polygonal faults. The negative relieves are discovered below the BSRs, which may result from pushing down seismic events due to high concentration of free gas below GHSZ (Figures 5 and 7).

Biogenic gas migration may occupy partial gas component in gas hydrate in and above middle Miocene, while thermogenic hydrocarbon source rocks host in early Oligocene Yacheng formation, late Oligocene Lingshui formation, and Miocene Sanya formation [31]. Zhu et al. [32] tested gases released from acid hydrocarbon on 127 shallow sediment samples in QDNB, and indicated the existence of thermogenic gases with methane concentration $10 \sim 243.5 \mu \mathrm{Lkg}^{-1}$, carbon isotope $-43.8 \% \sim-26.6 \%$, and $\mathrm{C} 1 /(\mathrm{C} 2+\mathrm{C} 3) 10 \sim$ 30. It is inferred that focus fluid flows with large volume of thermogenic gas from the source rocks, together with shallow biogenic gas, may mix and migrate upward along the polygonal fault system and form gas hydrates in locations of appropriate temperature and pressure. Hence, polygonal faults serve as a pathway linking thermogenic gas and shallow biogenic gas to the reservoirs of gas hydrates.

\section{Conclusions}

Researches based on high resolution 3D and 2D seismic data show that polygonal faults are tensional normal faults with fault lengths from 100 to $1500 \mathrm{~m}$, fault spaces from 40 to $800 \mathrm{~m}$, and throws from 10 to $40 \mathrm{~m}$. The layer-bound sequence surfaces, two or more tiers, and polygonal geometry view pattern in plane can be recognized. Occurrence of gas hydrates in deep water of South China Sea is considered to be related to fluid flow through the polygonal fault system. Polygonal faults link thermogenic gas and shallow biogenic 
gas to GHSZ, serving as pathways to migrate gas upwards to form gas hydrates.

\section{Acknowledgments}

The authors thank the Hangzhou Institute of Geology of PetroChina for permission to release these data in this paper. They gratefully acknowledge the reviewers for further suggestions and grammar revision. The research work was supported by the National Natural Science Foundation of China (no. 40930845), International Science \& Technology Cooperation program of China (no. 2010DFA21740), and the National Basic Research Program (no. 2009CB219505).

\section{References}

[1] J. A. Cartwright and D. N. Dewhurst, "Layer-bound compaction faults in fine-grained sediments," Bulletin of the Geological Society of America, vol. 110, no. 10, pp. 1242-1257, 1998.

[2] J. A. Cartwright, "Episodic basin-wide hydrofracturing of overpressured Early Cenozoic mudrock sequences in the North Sea Basin," Marine and Petroleum Geology, vol. 11, no. 5, pp. 587-607, 1994.

[3] J. P. Henriet, M. de Batist, and W. van Vaerenbergh, "Seismic facies and clay tectonic features of the Ypresian clay in the Southern North Sea," Bulletin van de Belgische Vereniging voor Geologie, vol. 97, pp. 457-472, 1989.

[4] J. P. Henriet, D. Batist, and M. Verschuren, "Early fracturing of Palaeogene clays, southernmost North Sea: relevance to mechanisms of primary hydrocarbon migration," in Generation, Accumulation and Production of Europe's Hydrocarbons, A. M. Spencer, Ed., pp. 217-227, Oxford University Press, Oxford, 1991.

[5] W. G. Higgs and K. R. McClay, "Analogue sandbox modeling of Miocene extensional faulting in the Outer Moray Firth," Geology Society of London, vol. 71, pp. 141-162, 1993.

[6] J. A. Cartwright, "Episodic basin-wide fluid expulsion from geopressured shale sequences in the North Sea Basin," Geology, vol. 22, no. 5, pp. 447-450, 1994.

[7] J. A. Cartwright and L. Lonergan, "Volumetric contraction during the compaction of mudrocks: a mechanism for the development of regional-scale polygonal fault systems," Basin Research, vol. 8, no. 2, pp. 183-193, 1996.

[8] N. R. Goulty, "Geomechanics of polygonal fault systems: a review," Petroleum Geoscience, vol. 14, no. 4, pp. 389-397, 2008.

[9] S. Wu, Q. Sun, T. Wu, S. Yuan, Y. Ma, and G. Yao, "Polygonal fault and oil-gas accumulation in deep-water area of Qiongdongnan Basin," Shiyou Xuebao/Acta Petrolei Sinica, vol. 30, no. 1, pp. 22-26, 2009 (Chinese).

[10] Q. Sun, S. Wu, F. Lü, and S. Yuan, "Polygonal faults and their implications for hydrocarbon reservoirs in the southern Qiongdongnan Basin, South China Sea," Journal of Asian Earth Sciences, vol. 39, no. 5, pp. 470-479, 2010.

[11] X. N. Xie, R. D. Müller, S. Li, Z. Gong, and B. Steinberger, "Origin of anomalous subsidence along the Northern South China Sea margin and its relationship to dynamic topography," Marine and Petroleum Geology, vol. 23, no. 7, pp. 745$765,2006$.
[12] B. C. Yao, "Gas hydrates in the South China Sea," Journal of Tropical Oceanography, vol. 20, no. 2, pp. 20-28, 2001 (Chinese).

[13] B. C. Yao, "The forming condition and distribution characteristics of the gas hydrate in the South China Sea," Marine Geology \& Quaternary Geology, vol. 25, no. 2, pp. 81-90, 2005 (Chinese).

[14] D. F. Chen, X. X. Li, and B. Xia, "Distribution of gas hydrate stable zones and resource prediction in the Qiongdongnan basin of the South China Sea," Chinese Journal of Geophysics, vol. 47, no. 3, pp. 483-489, 2004.

[15] S. Wu, G. Zhang, Y. Huang, J. Liang, and H. K. Wong, "Gas hydrate occurrence on the continental slope of the northern South China Sea," Marine and Petroleum Geology, vol. 22, no. 3, pp. 403-412, 2005.

[16] X. J. Wang, S. G. Wu, D. D. Dong, Y. H. Gong, and C. Chai, "Characteristics of gas chimney and its relationship to gas hydrate in Qiongdongnan basin," Marine Geology \& Quaternary Geology, vol. 28, no. 3, pp. 103-108, 2008 (Chinese).

[17] Q. Ma, S. Chen, Q. Zhang, S. Guo, and S. Wang, Overpressure Basins and Hydrocarbon Distribution, Geological Press, Beijing, China, 2000.

[18] P. R. Miles, "Potential distribution of methane hydrate beneath the European continental margins," Geophysical Research Letters, vol. 22, no. 23, pp. 3179-3182, 1995.

[19] X. Wang, S. Wu, S. Yuan et al., "Geophysical signatures associated with fluid flow and gas hydrate occurrence in a tectonically quiescent sequence, Qiongdongnan Basin, South China Sea," Geofluids, vol. 10, no. 3, pp. 351-368, 2010.

[20] L. He, K. Wang, L. Xiong, and J. Wang, "Heat flow and thermal history of the South China Sea," Physics of the Earth and Planetary Interiors, vol. 126, no. 3-4, pp. 211-220, 2001.

[21] C. S. Jin, J. Y. Wang, and G. X. Zhang, "Factors affecting natural gas hydrate stability zone in the South China Sea," Mineral Deposits, vol. 24, no. 5, pp. 388-397, 2005 (Chinese).

[22] X. Shi, X. Qiu, K. Xia, and D. Zhou, "Characteristics of surface heat flow in the South China Sea," Journal of Asian Earth Sciences, vol. 22, no. 3, pp. 265-277, 2003.

[23] L. Chen and H. B. Song, "Research progress on seismic detection methods of natural gas seepage on the seabed," Natural Gas Industry, vol. 26, no. 7, pp. 35-39, 2006 (Chinese).

[24] J. X. He, B. Xia, S. L. Zhang, P. Yan, and H. L. Liu, "Origin and distribution of mud diapirs in the Yinggehai basin and their relation to the migration and accumulation of natural gas," Geology in China, vol. 33, no. 6, pp. 1336-1344, 2006 (Chinese).

[25] A. Gay, M. Lopez, P. Cochonat, M. Séranne, D. Levaché, and G. Sermondadaz, "Isolated seafloor pockmarks linked to BSRs, fluid chimneys, polygonal faults and stacked OligoceneMiocene turbiditic palaeochannels in the Lower Congo Basin," Marine Geology, vol. 226, no. 1-2, pp. 25-40, 2006.

[26] S. Hustoft, J. Mienert, S. Bünz, and H. Nouzé, "Highresolution $3 \mathrm{D}$-seismic data indicate focussed fluid migration pathways above polygonal fault systems of the mid-Norwegian margin,” Marine Geology, vol. 245, no. 1-4, pp. 89-106, 2007.

[27] C. Berndt, S. Bünz, and J. Mienert, "Polygonal fault systems on the mid-Norwegian margin: a long term source for fluid flow," in Subsurface Sediment Mobilization, P. Rensbergen, R. R. Hillis, A. J. Maltman, and C. K. Morley, Eds., pp. 283-296, Geology Society of London, London, UK, 2003. 
[28] J. Cullen, D. C. Mosher, and K. Louden, "The mohican channel gas hydrate zone, scotian slope: geophysical structure," in Proceedings of the 6th International Conference on Gas Hydrates, Vancouver, Canada, 2008.

[29] J. Watterson, J. Walsh, A. Nicol, P. A. R. Nell, and P. G. Bretan, "Geometry and origin of a polygonal fault system," Journal of the Geological Society, vol. 157, no. 1, pp. 151-162, 2000.

[30] S. J. Roberts and J. A. Nunn, "Episodic fluid expulsion from geopressured sediments," Marine and Petroleum Geology, vol. 12, no. 2, pp. 195-204, 1995.

[31] J. X. He, B. Xia, D. S. Sun, S. L. Zhang, and B. M. Liu, "Hydrocarbon accumulation, migration and play targets in the Qiongdongnan Basin, South China Sea," Petroleum Exploration and Development, vol. 33, no. 1, pp. 53-58, 2006 (Chinese).

[32] Y. H. Zhu, B. H. Wu, X. R. Luo, and G. X. Zhang, "Geochemical characteristics of hydrocarbon gases and their origin from the sediments of the South China Sea," Geoscience, vol. 22, no. 3, pp. 407-414, 2008 (Chinese). 

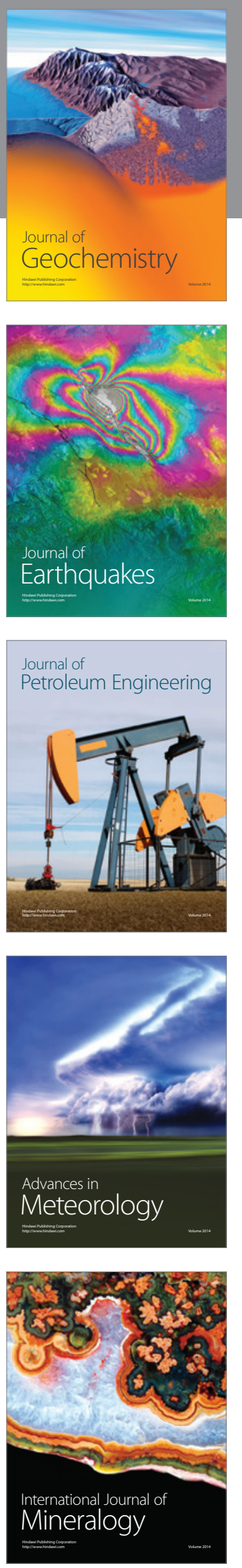
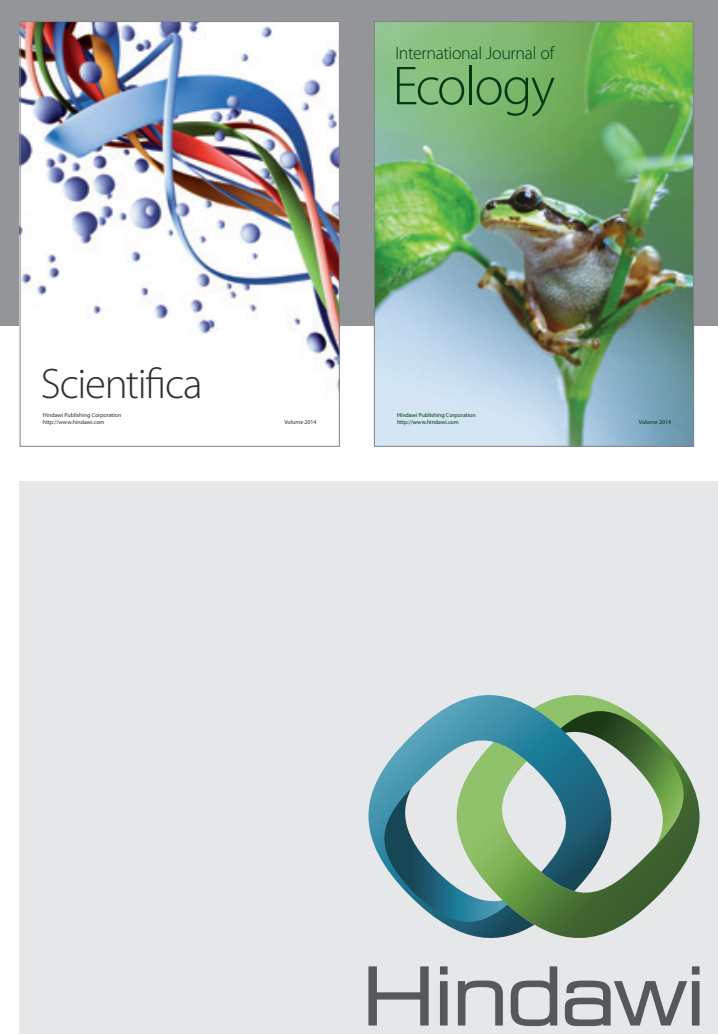

Submit your manuscripts at http://www.hindawi.com
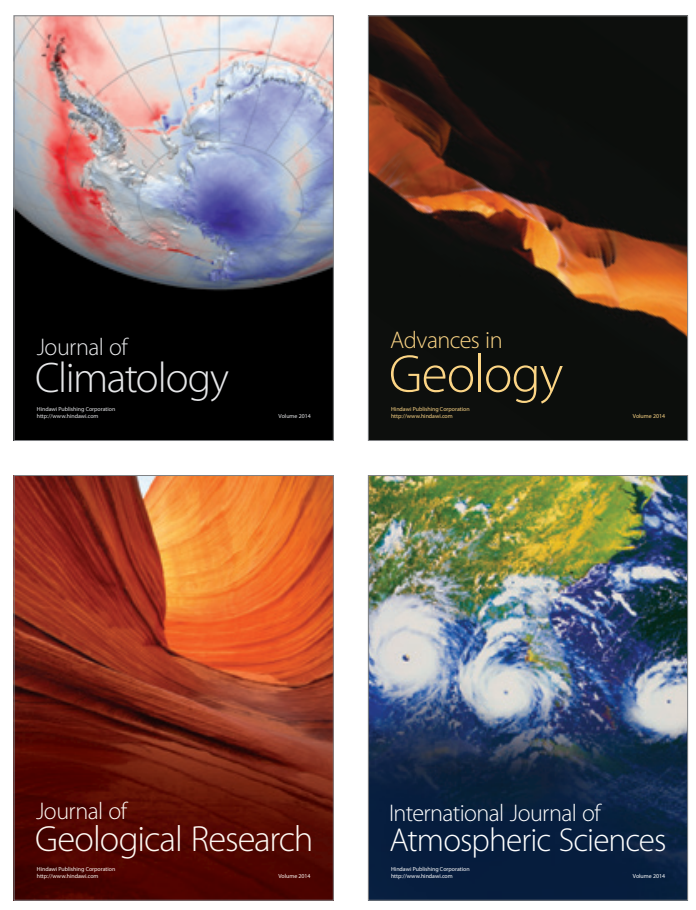
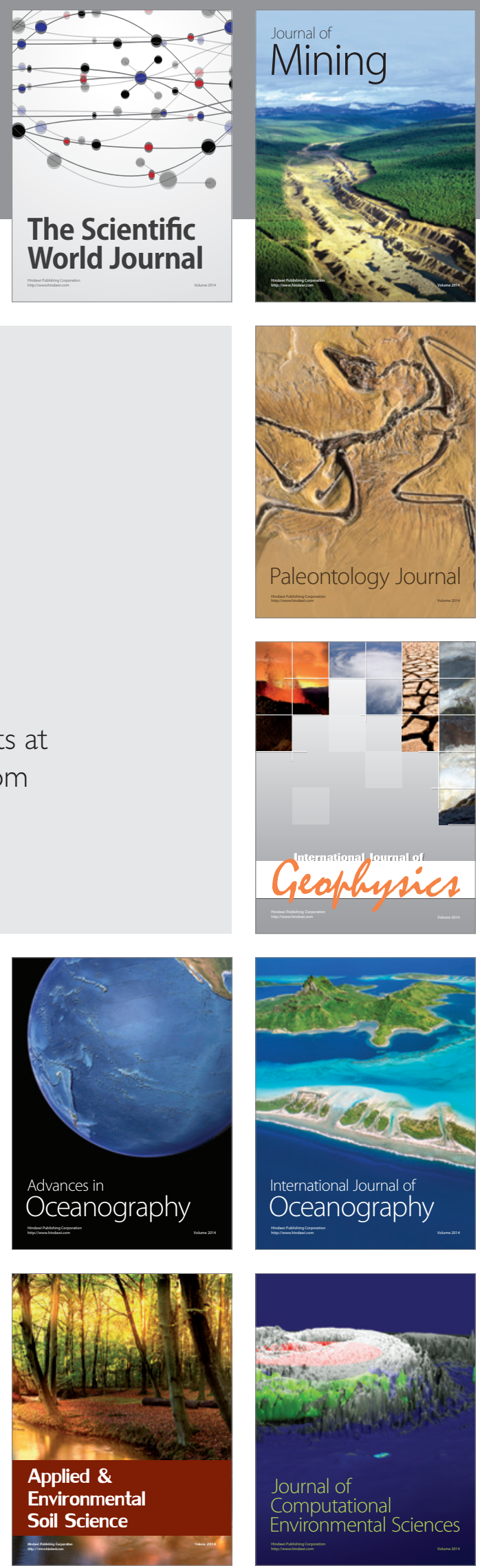